\title{
Design of Experiment Assisted UV-Visible Spectrophotometric and RP-HPLC Method Development for Ambrisentan Estimation in Bulk and Formulations
}

\author{
Shanta K. Adiki ${ }^{1}$, Prashanti $M^{1}$, Baishakhi Dey ${ }^{2}$, Prakash Katakam, ${ }^{3, *}$, Fathi H. Assaleh ${ }^{3}$, Nagiat T. Hwisa ${ }^{3}$, \\ Rajeev K. Singla ${ }^{4}$, Babu R. Chandu \\ ${ }^{1}$ Department of Pharmaceutical Analysis, Nirmala College of Pharmacy, Guntur, India \\ ${ }^{2}$ School of Medical Science \& Technology, Indian Institute of Technology, Kharaghpur, India \\ ${ }^{3}$ Faculty of Pharmacy, University of Zawia, Az Zawiyah, Libya \\ ${ }^{4}$ Division of Biotechnology, Netaji Subhas Institute of Technology, New Delhi, India \\ *Corresponding author: pkatakam9@gmail.com
}

Received May 09, 2014; Revised June 03, 2014; Accepted June 04, 2014

\begin{abstract}
Design of experiment (DOE) approach reinforces the robustness of the method being developed. This was employed for UV-visible (200-400 nm and 400-800 nm respectively) and RP-HPLC method development using $\mathrm{C}_{18}$ inertsil column and optimization of variables for ambrisentan (ABN) estimation in bulk and formulations. A two-level full factorial design assisted development of a visible spectroscopic method based on the principle of oxidation and coupling reaction of ABN with 3-methyl-2-benzothiazolinone hydrazone (MBTH reagent) in presence of $\mathrm{FeCl}_{3}$ to form bluish-green chromogen which is detectable in the visible range. second method estimates $\mathrm{ABN}$ in bulk and tablet dosage forms in the UV range using $\mathrm{pH} 7.4$ phosphate buffer and the third one is a rapid, simple, stability indicating RP-HPLC method using a degassed mixture of orthophosphoric acid (OPA, 0.05M): acetonitrile (40:60) as mobile phase with water: acetonitrile (30:70) as diluent using PDA detector set at $264 \mathrm{~nm}$ for routine estimation of $\mathrm{ABN}$ in bulk and pharmaceutical dosage forms. Experimental design, data analysis and contour plots were developed using Minitab ${ }^{\circledR}$ 16.2.4 trial version (Minitab Inc). The percent assay of ABN detected by visible spectroscopy was $100.58 \pm 101.37 \%$ with RSD value $0.38 \%$, by UV spectroscopy it was $99.1 \pm 99.8 \%$ with $0.5 \%$ RSD value and by RP-HPLC it was found $100.9 \%$. The values of method validation parameters of three methodologies were found within the acceptance limits. The three methodologies could be regarded as specific, accurate, precise, with significant stability and robustness for routine estimation of ABN in bulk and tablet dosage forms.
\end{abstract}

Keywords: Ambrisentan, Antihypertensive, Experimental design, RP-HPLC, Spectrophotometric, Validation

Cite This Article: Shanta K. Adiki, Prashanti M, Baishakhi Dey, Prakash Katakam, Fathi H. Assaleh, Nagiat T. Hwisa, Rajeev K. Singla, and Babu R. Chandu, "Design of Experiment Assisted UV-Visible Spectrophotometric and RP-HPLC Method Development for Ambrisentan Estimation in Bulk and Formulations.” World Journal of Analytical Chemistry, vol. 2, no. 2 (2014): 23-30. doi: 10.12691/wjac-2-2-2.

\section{Introduction}

Analytical method development is an integral part of preformulation and formulation development research. With the advancements in pharmaceutical researches, development of both small and large scale pharmaceutical industries worldwide, the number of drugs and drug formulations are increasing in the market day by day which in many cases may be new entities or partial modifications of the existing drugs or novel dosage forms. The assay procedure of such drugs or formulations may not be official in pharmacopeias. Hence, there arises dire need to develop rapid, simple, sensitive, specific, cost effective, validated and stability indicating analytical methods for the routine analysis of drugs. Analytical method development is an imperative necessity since the design of the drug delivery system is related to it. Moreover drug analysis is also necessary in various steps of formulation design and dissolution studies [1-5]. Sophisticated hyphenated techniques like LC-MS, LC-ESI-MS/MS though introduced into analytical research but relatively expensive, necessitates complicated sample preparation steps, time consuming and obviously not preferable to small scale industries for routine and rapid analysis [6,7]. UV-visible spectrophotometric method is one of the earliest, yet easy, sensitive, relatively cost effective method applied for drug estimation in both small and large scale pharmaceutical industries. Properly validated, stability indicating HPLC methods if be precise, rapid and simple in operation, is of immense utility in routine quality control [2-6]. 
Ambrisentan (ABN), chemically, (2S)-2-(4,6-dimethyl pyrimidin-2-yloxy) -3-methoxy-3, 3-diphenyl propionic acid, an orally active antihypertensive drug used in the treatment of pulmonary atrial hypertension to improve exercise capacity and delay clinical worsening; is a nonpeptide, highly selective endothelin-1 type A receptor antagonist. Endothelin (ET) is a peptide which elevates blood pressure by constriction of blood vessels. There are two classes of ET receptors namely, type A and type B. The binding of ET to type A receptors causes vasoconstriction while the binding to those of type $B$ causes vasodilatation. ABN has high affinity to ET-type A receptor, thereby blocking its effect and decreasing blood pressure in lungs. The thickening of blood vessels in the lungs and heart is also inhibited by $\mathrm{ABN}[4,5,6]$.

To the best of our knowledge estimation of $\mathrm{ABN}$ is not official in any of the Pharmacopeias. Literature survey showed LC-ESI-MS/MS [6], enantio-selective liquid chromatography [7], spectrophotometry [8,9,10] and UV-HPLC methods for the estimation of $\mathrm{ABN}$ [11,12,17,18,19,20,21]. Considering the clinical significance of ABN, there is a need to develop simple, rapid, cost effective, validated analytical techniques for its routine estimation in formulations. The current research focuses to develop three methodologies for ABN quantification, one of which is based on oxidation of $A B N$ followed by coupling with 3 methyl-2-benzothiazolinone hydrazone (MBTH) in presence of $\mathrm{FeCl3}$ to form bluish green color chromogen, detectable in visible spectroscopic range. The second method estimates $\mathrm{ABN}$ in bulk and tablet dosage forms in the UV range using $\mathrm{pH} 7.4$ phosphate buffer and the third method is a rapid, simple, stability indicating RP-HPLC method for routine estimation of $\mathrm{ABN}$ in bulk and pharmaceutical dosage forms.

Developing and optimizing a new analytical method is a complex procedure necessitating simultaneous determination of several method parameters. Traditional trial-error approach is not only time consuming but provides an apparent optimization method. Information relating to factors influencing process output measures or product quality are not available. The current research utilized experimental design approach for evaluating the significance of the studied factors and optimizing the visible spectroscopic and chromatographic conditions $[13,16]$.

\section{Materials and Methods}

\subsection{Chemicals and Reagents}

Pure ambrisentan was gratis sample from Cystron Laboratories, Vijayawada, India. HPLC grade acetonitrile, methanol and water were purchased from Merck, India. Sodium carbonate, $\mathrm{HCl}$, orthophosphoric acid, ferric chloride, triethyl amine and other chemicals are of AR grade from Merck, India.

\subsection{Instrumentation}

Liquid chromatographic system (Waters, with EMPOWER2 ${ }^{\circledR}$ software using PDA detector, India), UVvisible spectrophotometer (Thermo Scientific, Aquamate Plus, India), Electronic balance (Shimadzu, Japan),
Sonicator (Cyber labs, India), pH meter (Datla instruments, DI-45, India) and Hot Plate (Shital Scientific Industries, India) were employed in the study.

\subsection{Software}

Experimental design, data analysis and contour plots were developed using Minitab ${ }^{\circledR}$ 16.2.4 trial version (Minitab Inc).

\subsection{Estimation of ABN by visible spectroscopy}

The method is based on the principle of oxidation and coupling reaction of ABN with 3-methyl-2benzothiazolinone hydrazone (MBTH reagent) in presence of $\mathrm{FeCl}_{3}$ to form bluish-green chromogen which is detectable in the visible range. The proposed reaction scheme is presented in Figure 1.

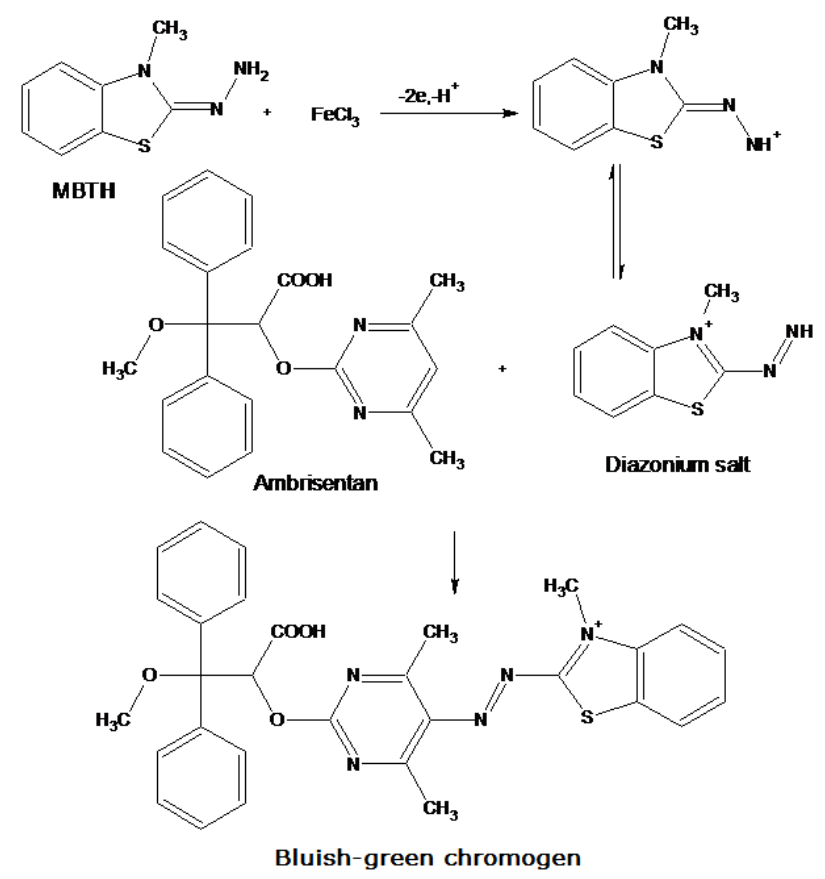

Figure 1. Proposed reaction scheme showing formation of bluish-green chromogen

\subsubsection{Experimental Design for Optimization}

A two-level full factorial design was employed to evaluate the effect of four independent factors, viz. MBTH reagent concentration (X1), volume of $\mathrm{MBTH}$ reagent (X2), $\mathrm{FeCl}_{3}$ concentration (X3) and Volume of $\mathrm{FeCl}_{3}$ solution (X4) on absorbance Y. The table matrix of the two-level full factorial design and experimental runs is provided in Table 1. From the resultant design matrix it was observed that maximum absorbance $(\mathrm{Y})$ was shown with $2 \% \mathrm{MBTH}$ and $2 \% \mathrm{FeCl}_{3}$ each of $2 \mathrm{~mL}$ and $1.5-2$ $\mathrm{mL}$ respectively. Thus in the optimized method, $10 \mathrm{mg}$ of ABN was dissolved in $10 \mathrm{~mL}$ methanol to get a concentration of $1000 \mu \mathrm{g} / \mathrm{mL}$ (standard stock solution) and further diluted with the same solvent to get a concentration of $10 \mu \mathrm{g} / \mathrm{mL}$. This solution was scanned in the range of $400-800 \mathrm{~nm}$ against blank and $625 \mathrm{~nm}$ was selected as the $\lambda_{\max }$ for analysis of ABN by MBTH. To each flask, $1.5-2 \mathrm{~mL}$ of aqueous $\mathrm{FeCl}_{3}$ solution $(2 \%$ in distilled water) and $2 \mathrm{~mL}$ of $\mathrm{MBTH}$ reagent $(2 \%$ in 
distilled water) were added. Volumes were adjusted in each tube with distilled water. The absorbance of bluish green colored chromogen was measured at $625 \mathrm{~nm}$ against the blank. Different aliquots of ABN were prepared in 10 $\mathrm{mL}$ volumetric flasks in the concentrations of 10-30 $\mu \mathrm{g} / \mathrm{mL}$. The amount of $\mathrm{ABN}$ present in the sample solution was computed from its calibration curve [14].

\subsubsection{Validation of the Method}

The above method was validated as per ICH guidelines in terms of linearity, accuracy, precision, robustness, LOD and LOQ [22]. The linearity range for the estimation of ABN by MBTH was determined by preparing aliquots in the concentration range of $10-30 \mu \mathrm{g} / \mathrm{mL}$ and absorbances measured at $625 \mathrm{~nm}$. Calibration curves (concentrations vs absorbance) were plotted and $\mathrm{R}^{2}$ value not less than 0.99 was regarded as acceptance criterion.

Accuracy of the proposed method was ascertained by recovery studies using analyte recovery method and percent recovery for $\mathrm{ABN}$ in the range of 98.8-99.6\% were set as the acceptance criterion. The precision was studied by intra-day variations in the test method of ABN and expressed as percent relative standard deviation (RSD) where these values should not be greater than $2 \%$. The LOD and LOQ parameters were determined from the calibration curves basing on the formulae: $\mathrm{LOD}=3.3 \mathrm{\sigma} /$ $\mathrm{S}$ and $\mathrm{LOQ}=10 \sigma / \mathrm{S}$, where $\mathrm{S}$ is slope of calibration curve and $\sigma$ is standard deviation of y-intercepts of calibration graph.

The robustness of an analytical procedure is a measure of its capacity to remain unaffected by small but deliberate variations in the process parameters. As a measure of robustness of the method, intentional alterations were made in the absorbance maximum to evaluate the impact of the method. A $20 \mu \mathrm{g} / \mathrm{mL}$ of $\mathrm{ABN}$ was prepared by above procedure and the absorbance was observed at 627 and $623 \mathrm{~nm}$.

\subsubsection{Assay of $A B N$}

Accurately weighed 10 tablets $(10 \mathrm{mg}$ ) were pooled and powdered of which $10 \mathrm{mg}$ equivalent of $\mathrm{ABN}$ was transferred into $10 \mathrm{~mL}$ volumetric flask, dissolved in methanol, sonicated, filtered through $0.45 \mu \mathrm{m}$ filter (Millipore $^{\circledR}$ ), and properly diluted to get a solution concentration of $100 \mu \mathrm{g} / \mathrm{mL}$. The absorbance of $\mathrm{ABN}$ sample solution at $20 \mu \mathrm{g} / \mathrm{mL}$ concentration was measured at $625 \mathrm{~nm}$ against blank and the percentage assay was calculated using the formula:

$$
\text { Assay } \%=\frac{\mathrm{AT}}{\mathrm{AS}} \times \frac{\mathrm{WS}}{\mathrm{DS}} \times \frac{\mathrm{DT}}{\mathrm{WT}} \times \frac{\mathrm{P}}{100} \times \frac{\text { Avg. Wt }}{\text { Label claim }} \times 100
$$

where, AT is absorbance of test, WS $=$ wt. of standard sample, WT= wt. of test sample, AS is absorbance of standard, DS is dilution factor of standard, DT is dilution factor of test and $\mathrm{P}$ is potency of standard.

\subsection{Estimation of $\mathrm{ABN}$ by UV Spectroscopy}

The $0.1 \mathrm{M}$ pH 7.4 buffer solution was prepared by dissolving $2.62 \mathrm{~g}$ of monobasic sodium phosphate and $11.5 \mathrm{~g}$ of anhydrous dibasic sodium phosphate in $1000 \mathrm{~mL}$ of water. Stock solution was prepared by dissolving $10 \mathrm{mg}$ of $\mathrm{ABN}$ in $\mathrm{pH} 7.4$ phosphate buffer and diluted to get a concentration of $10 \mu \mathrm{g} / \mathrm{mL}$. This solution was scanned in
200-400 nm range against blank and $262.5 \mathrm{~nm}$ was selected as $\lambda_{\max }$ for analysis of ABN. The standard calibration curve was constructed with the standard stock solution in the concentration range of $10-50 \mu \mathrm{g} / \mathrm{mL}$ and absorbances were measured at $262.5 \mathrm{~nm}$. The UV method developed was validated in terms of linearity, accuracy, precision, LOD, LOQ and robustness as discussed above.

For preparation of $\mathrm{ABN}$ sample solution, accurately weighed 10 tablets of $\mathrm{ABN}$ were powdered of which 10 mg equivalent of the drug was transferred into $10 \mathrm{~mL}$ volumetric flask, dissolved in $7 \mathrm{~mL}$ of phosphate buffer, sonicated well, filtered through $0.45 \mu \mathrm{m}$ filter (Millipore ${ }^{\circledR}$ ) and diluted to get a concentration of $100 \mu \mathrm{g} / \mathrm{mL}$. The absorbance of ABN sample $(20 \mu \mathrm{g} / \mathrm{mL})$ was measured at $262.5 \mathrm{~nm}$ against blank and the percentage assay was calculated using the above formula.

\subsection{Estimation of ABN by RP-HPLC}

\subsubsection{Experimental Design and Optimization of Mobile Phase}

Before proceeding to the optimized RP-HPLC chromatographic conditions for $\mathrm{ABN}$ estimation, numerous trails were conducted with different mobile phase compositions. Amongst fifteen preliminary trials, injection volume $(10 \mu \mathrm{L})$ and flow rate $(1 \mathrm{~mL} / \mathrm{min})$ were kept constant. The absorbances were measured between 260-264 nm wavelength and trial runs were performed using different mobile phase compositions. Using triethylamine (TEA) as mobile phase with $\mathrm{pH}$ adjusted by 0.05M orthophosphoric acid (OPA), a very broad peak was obtained. The same result was reported when methanol was used as diluents, when water: methanol (80:20) was used as diluents the peak retention time became unduly delayed. On changing the mobile phase composition to TEA: OPA: acetonitrile (ACN) with diluents of varying compositions like water: acetonitrile (50:50) and methanol: water (80:20), the peaks were not within symmetry limits with a noisy baseline indicating instability of the drug in the mobile phase. A two-level full factorial design $[13,14,15,16]$ was employed to evaluate the effect of three independent factors, viz. wavelength (X1), flow rate (X2) and OPA percentage in mobile phase (X3) on retention time (Y1) and USP tailing factor (Y2). The table matrix of the two-level full factorial design and experimental runs is provided in Table 2.

The optimized chromatographic conditions for ABN estimation were obtained with isocratic separation mode in a $\mathrm{C}_{18}$ inertsil column (250 $\left.\mathrm{mm} \times 4.6 \mathrm{~mm}, 5 \mu \mathrm{m}\right)$ using a degassed mixture of orthophosphoric acid (OPA): acetonitrile (40:60) as mobile phase with water: acetonitrile (30:70) as diluent, injection volume $(20 \mu \mathrm{L})$, flow rate $(1.2 \mathrm{~mL} / \mathrm{min})$ and run time $(10 \mathrm{~min})$ with PDA (Photo Diode Array) detector set at $264 \mathrm{~nm}$.

The working standard and sample solutions of ABN were prepared by dissolving $65 \mathrm{mg} \mathrm{ABN}$ in diluent (water: acetonitrile, 30:70), sonicated and volume adjusted with diluent. Further dilutions from 5-50 $\mu \mathrm{g} / \mathrm{mL}$ concentration range were prepared from the standard and sample solutions, and the volume was adjusted in each case with mobile phase.

\subsubsection{System Suitability}


The ABN standard solution was injected into the HPLC system six times to evaluate the system suitability parameters from the standard chromatograms obtained by calculating the $\%$ RSD of retention times, tailing factor, theoretical plates and peak areas from six replicate injections. The limit of RSD and tailing factor were set below $2.0 \%$. The theoretical plate count was considered if less than 2000.

\subsubsection{Validation}

The proposed RP-HPLC method was validated as per ICH guidelines [22]. Accuracy of the proposed method was ascertained by recovery studies using analyte recovery method, where the drug substance was spiked with placebo in concentrations of 50, 100 and 150\% and the acceptable criteria of percent recovery for $\mathrm{ABN}$ were set as $98-102 \%$. Precision was studied in terms of repeatability (system precision), where $50 \mu \mathrm{g} / \mathrm{mL}$ of sample was injected for six times into the HPLC system as per test procedure. For method precision, from sample and stock solution, six replicates of standard and sample of 50 $\mu \mathrm{g} / \mathrm{mL}$ were prepared and injected into the HPLC system and\% RSD was calculated. Intermediate precision study or ruggedness of experimentation was carried out by different analyst, on different instrument and on different days. From the sample and stock solutions, six replicates of $50 \mu \mathrm{g} / \mathrm{mL}$ were prepared and injected into the HPLC system and\% RSD was calculated. The LOD and LOQ parameters were determined from the calibration curves basing on the formulae above.

As a measure of robustness of the method, deliberate alterations in the absorbance maximum, flow rate and mobile phase composition were made to evaluate the impact of the method. The $\lambda_{\max }$ was changed $( \pm 5 \mathrm{~nm}$ ) from $264 \mathrm{~nm}$ to 269 and $259 \mathrm{~nm}$. The flow rate was increased from original value $(1.2 \mathrm{~mL} / \mathrm{min})$ to $1.4 \mathrm{~mL} / \mathrm{min}$ and decreased to $0.8 \mathrm{~mL} / \mathrm{min}$. The ratio of mobile phase composition was also altered ( $\pm 10 \%$ ) from 40 :60 to $30: 70$ and 50:50. The tailing factor of ABN standard, RSD of asymmetry and retention time of ABN standard should not be more than $2 \%$ due to the intentional alterations of the said parameters.

\subsubsection{Interference Studies}

For studying blank and placebo interference, diluents and sample of placebo were injected in to the system with the objective that they should not show any peak at the retention time of analyte peak.

\subsubsection{Degradation Studies}

Chemical degradation studies such as; acidic, alkaline, oxidative, reductive, thermal, photolytic and humidity were conducted under stress conditions. From the sample stock solution, aliquots of $5 \mathrm{~mL}$ was transferred into 20 $\mathrm{mL}$ volumetric flask. To this, a $2 \mathrm{~mL}$ of $5 \%$ either $\mathrm{HCl}$ or $\mathrm{NaOH}$ was added for acid or alkali degradation studies respectively. In oxidation study, $2 \mathrm{~mL}$ of $\mathrm{H}_{2} \mathrm{O}_{2}$ was added, while in reduction study a $2 \mathrm{~mL}$ of sodium bisulphite was added. A small volume of diluent was added in all solutions, heated at $80^{\circ} \mathrm{C}$ on water bath for $20 \mathrm{~min}$ and cooled. The solutions were neutralized if necessary and the volume was adjusted with diluent. In case of thermal degradation studies the diluent was added to adjust the volume in the flask and the solution was heated at $105^{\circ} \mathrm{C}$ for $24 \mathrm{~h}$, whereas in photolytic degradation, the solution was kept under sunlight for $24 \mathrm{~h}$. During humidity stress investigation, the solution was subjected to $90 \% \mathrm{RH}$ at $25^{\circ} \mathrm{C}$ for $24 \mathrm{~h}$. The above solutions were filtered through $0.45 \mu \mathrm{m}$ nylon filter (Millipore ${ }^{\circledR}$ ) by discarding first $4 \mathrm{~mL}$ of solution. The blank solutions were prepared in the same manner without using samples.

\subsubsection{Bench Top Solution Stability of Standard and Sample}

To evaluate the solution stability, standard solution was prepared in single and samples were prepared in duplicate and kept on bench top. Solutions were analyzed at $0,4,8$, 12 and $24 \mathrm{~h}$. The differences of ABN content (\%) for bench top samples were calculated from the results as follows: Difference of assay (\%) $=\%$ of assay at each time interval (h) - \% assay at initial time (0 h).

\subsubsection{Assay of $A B N$ in Bulk and Dosage Forms}

Prior to the injection of drug (ABN) solutions, the column was equilibrated for at least $30 \mathrm{~min}$ with the mobile phase with a flow rate of $1.2 \mathrm{~mL} / \mathrm{min}$. Then $20 \mu \mathrm{L}$ of standard and sample solutions were injected for six and two times respectively and the drug content was determined. For the estimation of ABN in dosage forms, accurately weighed 10 tablets of ABN were powdered. A $10 \mathrm{mg}$ equivalent of the drug was transferred into $10 \mathrm{~mL}$ volumetric flask, the diluent was added, sonicated well, filtered through $0.45 \mu \mathrm{m}$ filter (Millipore ${ }^{\circledR}$ ) and suitably diluted and injected into HPLC system and the drug content was determined using standard curve.

Table 1. Two Level Full Factorial Design and Response Values for Visible Spectroscopy

\begin{tabular}{|c|c|c|c|c|c|c|c|c|}
\hline SO & RO & PT & B & X1 & X2 & X3 & X4 & Y \\
\hline 3 & 1 & 2 & 1 & 0 & 2 & 1 & 1 & 0.119 \\
\hline 25 & 2 & 0 & 1 & 1 & 1 & 1 & 1 & 0.757 \\
\hline 2 & 3 & 2 & 1 & 2 & 0 & 1 & 1 & 0.234 \\
\hline 15 & 4 & 2 & 1 & 1 & 0 & 2 & 1 & 0.384 \\
\hline 9 & 5 & 2 & 1 & 0 & 1 & 1 & 0 & 0.211 \\
\hline 12 & 6 & 2 & 1 & 2 & 1 & 1 & 2 & 0.627 \\
\hline 16 & 7 & 2 & 1 & 1 & 2 & 2 & 1 & 0.675 \\
\hline 17 & 8 & 2 & 1 & 0 & 1 & 0 & 1 & 0.201 \\
\hline 6 & 9 & 2 & 1 & 1 & 1 & 2 & 0 & 0.321 \\
\hline 19 & 10 & 2 & 1 & 0 & 1 & 2 & 1 & 0.119 \\
\hline 24 & 11 & 2 & 1 & 1 & 2 & 1 & 2 & 0.701 \\
\hline 4 & 12 & 2 & 1 & 2 & 2 & 1 & 1 & 0.715 \\
\hline 26 & 13 & 0 & 1 & 1 & 1 & 1 & 1 & 0.757 \\
\hline 23 & 14 & 2 & 1 & 1 & 0 & 1 & 2 & 0.118 \\
\hline 27 & 15 & 0 & 1 & 1 & 1 & 1 & 1 & 0.757 \\
\hline 13 & 16 & 2 & 1 & 1 & 0 & 0 & 1 & 0.113 \\
\hline 14 & 17 & 2 & 1 & 1 & 2 & 0 & 1 & 0.451 \\
\hline 1 & 18 & 2 & 1 & 0 & 0 & 1 & 1 & 0.381 \\
\hline 22 & 19 & 2 & 1 & 1 & 2 & 1 & 0 & 0.294 \\
\hline 7 & 20 & 2 & 1 & 1 & 1 & 0 & 2 & 0.632 \\
\hline 8 & 21 & 2 & 1 & 1 & 1 & 2 & 2 & 0.699 \\
\hline 5 & 22 & 2 & 1 & 1 & 1 & 0 & 0 & 0.471 \\
\hline 10 & 23 & 2 & 1 & 2 & 1 & 1 & 0 & 0.511 \\
\hline 20 & 24 & 2 & 1 & 2 & 1 & 2 & 1 & 0.712 \\
\hline 21 & 25 & 2 & 1 & 1 & 0 & 1 & 0 & 0.11 \\
\hline 18 & 26 & 2 & 1 & 2 & 1 & 0 & 1 & 0.213 \\
\hline 11 & 27 & 2 & 1 & 0 & 1 & 1 & 2 & 0.114 \\
\hline
\end{tabular}

$\mathrm{SO}=$ standard order, $\mathrm{RO}=$ run order, $\mathrm{PT}=\mathrm{Pt}$ type, $\mathrm{B}=$ blocks, $\mathrm{X} 1=$ $\mathrm{MBTH}$ reagent conc., $\mathrm{X} 2=$ volume of $\mathrm{MBTH}$ reagent, $\mathrm{X} 3=\mathrm{FeCl}_{3}$ concentration, $\mathrm{X} 4=\mathrm{FeCl}_{3}$ volume, $\mathrm{Y}=$ Absorbance 


\section{Results}

\subsection{Visible and UV Sspectroscopy}

The matrix of the two-level full factorial design and experimental runs for visible spectroscopy is provided in Table 1 . The contour plots of absorbance vs. $\mathrm{FeCl}_{3}$ and MBTH concentration and volume are presented in Figure 2. Data of the calibration curve of ABN by visible and UV spectroscopy are summarized in Table 2. The percent assay of ABN by visible spectroscopy was 100.58-101.37\% with $0.38 \%$ RSD and that detected by UV spectroscopy was found 99.1-99.8\% with 0.5\% RSD. Results of visible and UV spectroscopic method validations in terms of accuracy (recovery studies), precision, specificity, LOD and LOQ and robustness are provided in Table 3.

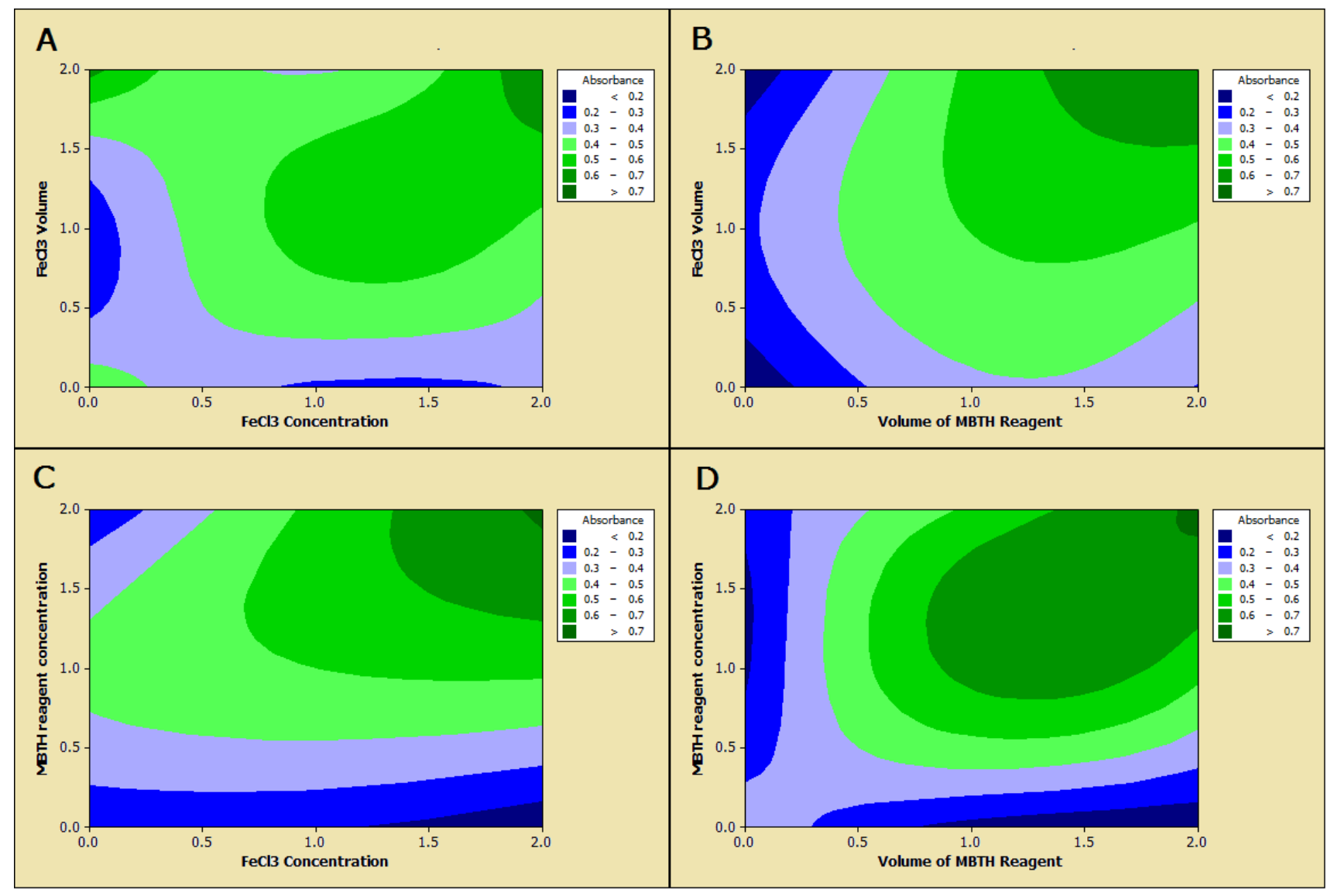

Figure 2. Contour plots of (A) absorbance vs $\mathrm{FeCl}_{3}$ concentration and volume, (B) absorbance vs. $\mathrm{FeCl}_{3}$ and $\mathrm{MBTH}$ volume, (C) absorbance vs. MBTH and $\mathrm{FeCl}_{3}$ concentration, and (D) absorbance vs. MBTH concentration and volume

Table 2. Data of the Calibration Curve of Ambrisentan by Visible and UV Spectroscopy

\begin{tabular}{|c|c|c|}
\hline Parameters & Visible method & UV method \\
\hline 95\% confidence intervals & & 0.01075 to 0.01237 \\
\hline Slope & 0.02407 to 0.02765 & -0.01815 to 0.03575 \\
\hline $\mathrm{y}$-intercept & -0.05349 to 0.02229 & -3.304 to 1.476 \\
\hline -intercept & -0.922 to 1.943 & 0.9985 \\
\hline Goodness of Fit & & $<0.0001$ \\
\hline $\mathrm{R}^{2}$ & 0.9986 & $\mathrm{y}=0.01156 \mathrm{x}+0.008800$ \\
\hline P value & $<0.0001$ & $0.01156 \pm 0.00025$ \\
\hline Equation & $\mathrm{y}=0.02586 \mathrm{x}-0.01560$ & $0.008800 \pm 0.008469$ \\
\hline Best fit values & & -0.7612 \\
\hline Slope & $0.02586 \pm 0.00056$ & \\
\hline $\mathrm{y}$-intercept & $-0.01560 \pm 0.01191$ & 0.6032 \\
\hline $\mathrm{x}$-intercept & & \\
\hline
\end{tabular}

Table 3. Validation Studies of Ambrisentan by Visible and UV Spectroscopy $(\mathrm{n}=6)$

\begin{tabular}{|c|c|c|c|}
\hline Parameters & Recommended limits & Visible method & UV method \\
\hline Specificity & No interferences & ${ }^{\mathrm{c}}$ & ${ }^{\mathrm{c}}$ \\
\hline Precision $^{\mathrm{a}}$ & NMT $^{\mathrm{b}} 2.00$ & 1.04 & 0.871 \\
\hline Accuracy, $\left.\%{ }^{\mathrm{a}}\right)$ & $98-102(2.00)$ & $98.8-99.6(0.439)$ & $100.3-100.9(0.527)$ \\
\hline LOD and LOQ & S:N ratio should be more than 3:1 & 2.7 and 8.3 & 1.2 and 3.6 \\
\hline Robustness $^{\mathrm{a}}$, (wave length, $\left.\mathrm{nm}\right)$ & NMT $^{\mathrm{b}} 2.00$ & $1.74(627)$ & $0.236(260.5)$ \\
\hline
\end{tabular}

${ }^{a}$ Percentage relative standard deviation, ${ }^{b}$ Not more than, ${ }^{\text {c} S p e c i f i c ~ n a t u r e ~ o f ~ m e t h o d, ~ n o ~ i n t e r f e r e n c e s ~ f o u n d ~}$ 


\subsection{RP-HPLC Method}

The response values of experimental runs of two-level full factorial design on HPLC method are given in Table 4. The different contour plots of the RP-HPLC experimental design are shown in Figure 3. As regards method validation, the linearity of the method was demonstrated over the concentration range of $10-300 \mu \mathrm{g} / \mathrm{mL}$ with $\mathrm{R}^{2}$ value not less than 0.99 and RSD of peak areas of the solution not more than $2.0 \%$. From the assay calculations, the assay of $\mathrm{ABN}$ tablets was found $100.9 \%$ and $0.35 \%$ RSD. There was no interference due to blank and placebo at the retention time of the analyte (Figure 4). The recovery of the spiked drug was found $100.7 \%$ with $0.23 \%$ RSD which falls within the acceptance criterion. Regarding precision, the system precision or repeatability of the method showed $0.632 \%$ RSD for the peak areas. The label claim for method precision was found $100.6 \%$ with $0.23 \%$ RSD. For intermediate precision or ruggedness of the method, $0.23 \%$ RSD was found for the peak area. Thus all parameters of precision studies were
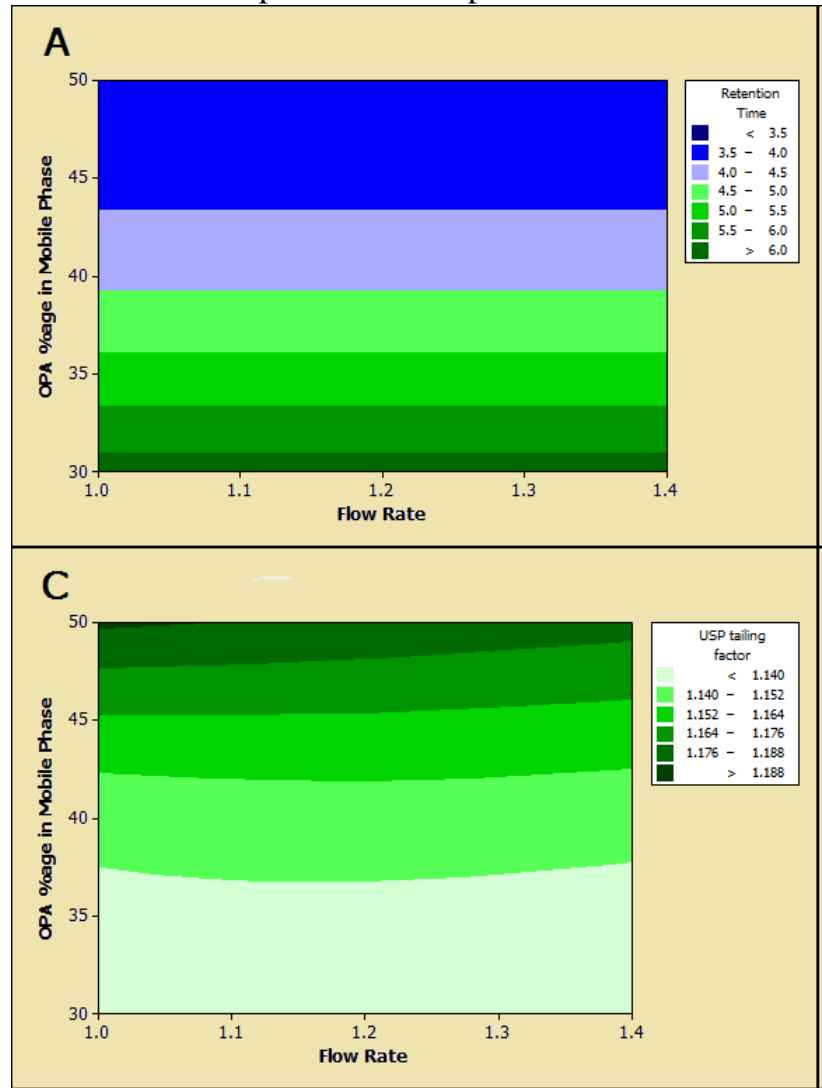

less than 2.0. LOD and LOQ values were calculated as 1.967 and 5.961 respectively.

Table 4. Two Level Full Factorial Design and Response Values for RP-HPLC

\begin{tabular}{|c|c|c|c|c|c|c|c|c|}
\hline SO & RO & PT & B & W & FR & OPA & RT & TF \\
\hline 9 & 1 & 2 & 1 & 264 & 1 & 30 & 6.2 & 1.14 \\
\hline 12 & 2 & 2 & 1 & 264 & 1.4 & 50 & 3.5 & 1.18 \\
\hline 5 & 3 & 2 & 1 & 259 & 1.2 & 30 & 6.2 & 1.13 \\
\hline 8 & 4 & 2 & 1 & 269 & 1.2 & 50 & 3.5 & 1.19 \\
\hline 11 & 5 & 2 & 1 & 264 & 1 & 50 & 3.5 & 1.19 \\
\hline 1 & 6 & 2 & 1 & 259 & 1 & 40 & 4.4 & 1.15 \\
\hline 7 & 7 & 2 & 1 & 259 & 1.2 & 50 & 3.5 & 1.18 \\
\hline 13 & 8 & 0 & 1 & 264 & 1.2 & 40 & 4.4 & 1.15 \\
\hline 6 & 9 & 2 & 1 & 269 & 1.2 & 30 & 6.2 & 1.14 \\
\hline 15 & 10 & 0 & 1 & 264 & 1.2 & 40 & 4.4 & 1.14 \\
\hline 14 & 11 & 0 & 1 & 264 & 1.2 & 40 & 4.4 & 1.15 \\
\hline 2 & 12 & 2 & 1 & 269 & 1 & 40 & 4.4 & 1.14 \\
\hline 10 & 13 & 2 & 1 & 264 & 1.4 & 30 & 6.2 & 1.13 \\
\hline 3 & 14 & 2 & 1 & 259 & 1.4 & 40 & 4.4 & 1.15 \\
\hline 4 & 15 & 2 & 1 & 269 & 1.4 & 40 & 4.4 & 1.14 \\
\hline
\end{tabular}

$\mathrm{SO}=$ standard order, $\mathrm{RO}=$ run order, $\mathrm{PT}=\mathrm{Pt}$ type, $\mathrm{B}=$ blocks, $\mathrm{W}=$ wave length $(\mathrm{nm})$, Flow rate $(\mathrm{mL} / \mathrm{min}), \mathrm{OPA}=$ OPA $\%$ in mobile phase, $\mathrm{RT}=$ retention time, $\mathrm{TF}=\mathrm{USP}$ tailing factor

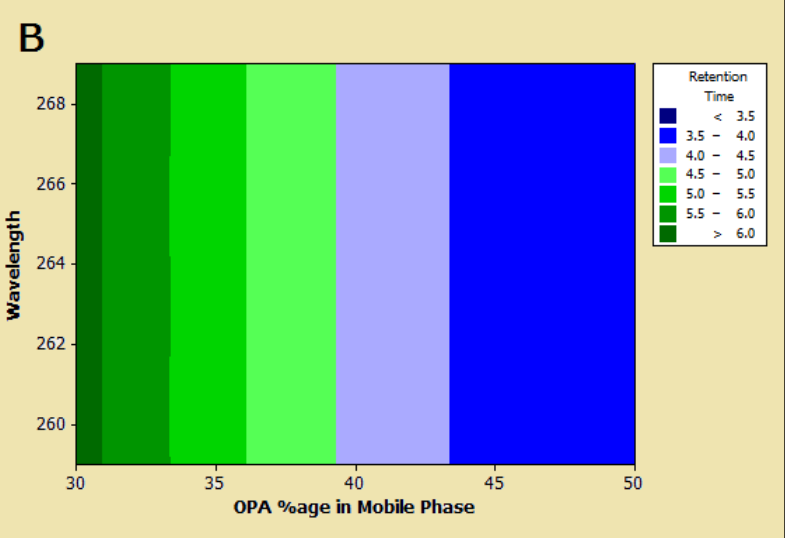

D

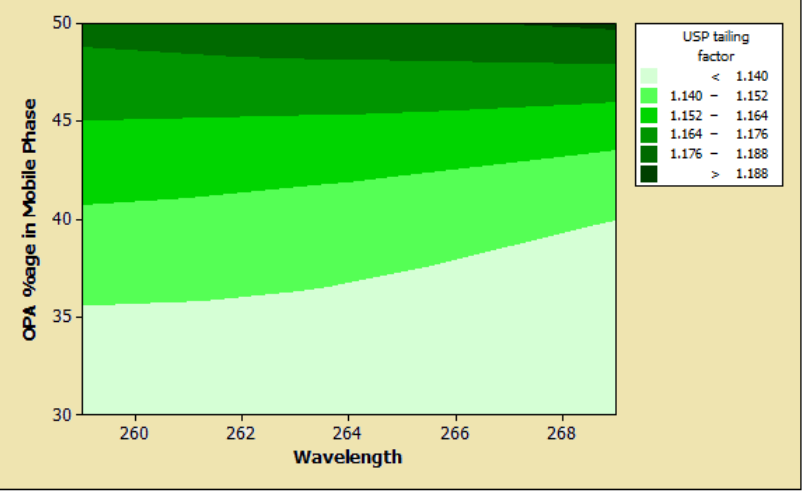

Figure 3. Contour plots of (A) retention time vs. OPA concentration and flow rate, (B) retention time vs. wavelength and OPA concentration, (C) USP tailing factor vs. OPA concentration and flow rate, and (D) USP tailing factor vs. OPA concentration and wavelength

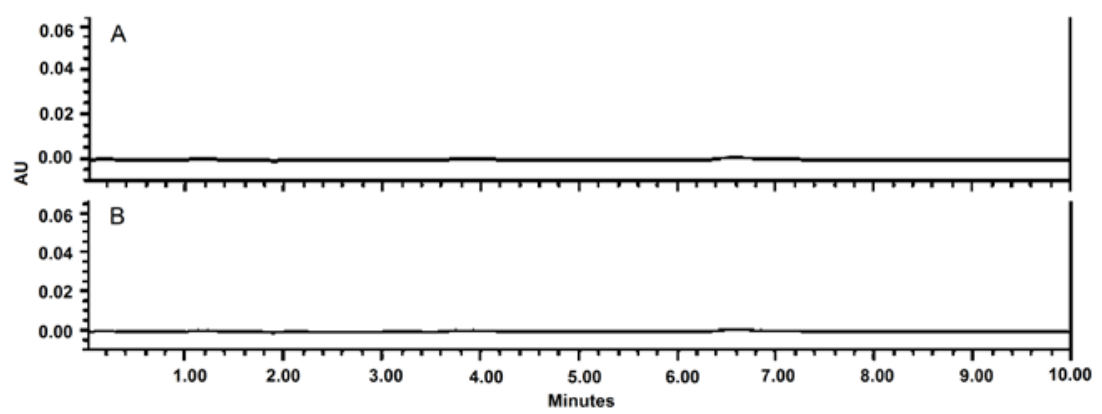

Figure 4. Typical chromatograms of (A) blank and (B) placebo 
Results of robustness of the method as determined by deliberate alterations in the ratios of mobile phase composition, flow rate and wavelength range are presented in Table 5. The results of forced degradation studies are presented in Table 6. Results of bench top solution stability studies are provided in Table 7 and Figure 5.

Table 5. Robustness of the Developed RP-HPLC $\operatorname{method}(\mathrm{n}=6)$

\begin{tabular}{|c|c|}
\hline Parameters & Peak area (\%RSD) $^{\mathrm{a}}$ \\
\hline Flow rate $(\mathrm{mL} / \mathrm{min})$ & 0.082 \\
\hline $1.2^{\mathrm{b}}$ & 0.086 \\
\hline $1.4^{\mathrm{c}}$ & 0.199 \\
\hline $0.8^{\mathrm{d}}$ & 0.082 \\
\hline Wave length $(\mathrm{nm})^{\mathrm{b}}$ & 0.184 \\
\hline $264^{\mathrm{b}}$ & 0.211 \\
\hline $269^{\mathrm{c}}$ & \\
\hline $259^{\mathrm{d}}$ & 0.082 \\
\hline Mobile phase & 0.870 \\
\hline $40: 60^{\mathrm{b}}$ & 0.420 \\
\hline $50: 50^{\mathrm{f}}$ & \\
\hline $30: 70^{\mathrm{f}}$ & \\
\hline
\end{tabular}

${ }^{\mathrm{a}}$ Percentage relative standard deviation, ${ }^{\mathrm{b}}$ Actual value, ${ }^{\mathrm{C}}$ Increased

${ }^{\mathrm{d}}$ Decreased, ${ }^{\mathrm{e}}$ Orthophosphoric acid:acetonitrile, ${ }^{\mathrm{f}}$ Altered ratio

Table 6. Forced Degradation Studies of Ambrisentan by Developed RP-HPLC Method $(\mathbf{n}=6)^{\mathrm{a}}$

\begin{tabular}{|c|c|c|c|c|c|c|c|}
\hline Type & RT & A & PC & TF & Deg & PA & PT \\
\hline Acid & 6.203 & 180271 & 7658 & 1.097 & 9.9 & 0.327 & 1.331 \\
\hline Alkali & 6.199 & 49127 & 7295 & 1.105 & 17.5 & 0.219 & 1.209 \\
\hline Peroxide & 6.212 & 587417 & 7565 & 1.032 & 25.7 & 0.356 & 1.190 \\
\hline Reduction & 6.206 & 320109 & 7794 & 1.110 & 17.0 & 0.232 & 1.222 \\
\hline Thermal & 6.199 & 220355 & 7746 & 1.096 & 9.3 & 0.368 & 1.384 \\
\hline Photolytic & 6.200 & 807180 & 7672 & 1.105 & 6.2 & 0.201 & 1.133 \\
\hline Humidity & 6.207 & 807291 & 7857 & 1.098 & 6.8 & 0.219 & 1.130 \\
\hline
\end{tabular}

Percentage relative, $\mathrm{RT}=$ retention time $(\mathrm{min}), \mathrm{A}=$ peak area, $\mathrm{PC}=\mathrm{USP}$ plate count, TF $=$ USP tailing factor, Deg $=\%$ degradation, $\mathrm{PA}=$ purity angle, PT = purity threshold. ${ }^{\mathrm{a}}$ All values comply with limits.

Table 7. Bench Top Solution Stability Studies of Ambrisentan by Developed RP-HPLC Method (n=6)

\begin{tabular}{|c|c|c|}
\hline Time ( h) & Label claim (\%) & \% RSD $^{\mathrm{a}}$ \\
\hline 0 & 99.5 & 0.5 \\
\hline 4 & 100.3 & 0.8 \\
\hline 8 & 101.2 & 1.7 \\
\hline 12 & 101.4 & 1.9 \\
\hline 24 & 101.5 & 2.0 \\
\hline
\end{tabular}

${ }^{\mathrm{a}}$ Percentage relative standard deviation

\section{Discussion}

A simple, rapid and properly validated UV spectroscopic method was developed for estimation of $\mathrm{ABN}$ in bulk and tablet dosage forms. Earlier work reported a single UV method [10] for ABN quantifications using acetonitrile as the diluent, whereas the current method employed $\mathrm{pH} 7.4$ phosphate buffer as the solvent. Two methods reported ABN estimation in visible range by forming colored ion-pair complexes of $\mathrm{ABN}$ with methylene blue and safranine [8] and by charge transfer reaction of $\mathrm{ABN}$ with dichloro benzoquinone derivatives [9]. But the present work applied principle of oxidation and coupling reaction of $\mathrm{ABN}$ with MBTH reagent in presence of $\mathrm{FeCl}_{3}$ to form bluish-green chromogen which is detectable in the visible range. The two reported RPHPLC methods [11,12] used mobile phase in gradient mode but we developed an optimized method using isocratic separation mode.
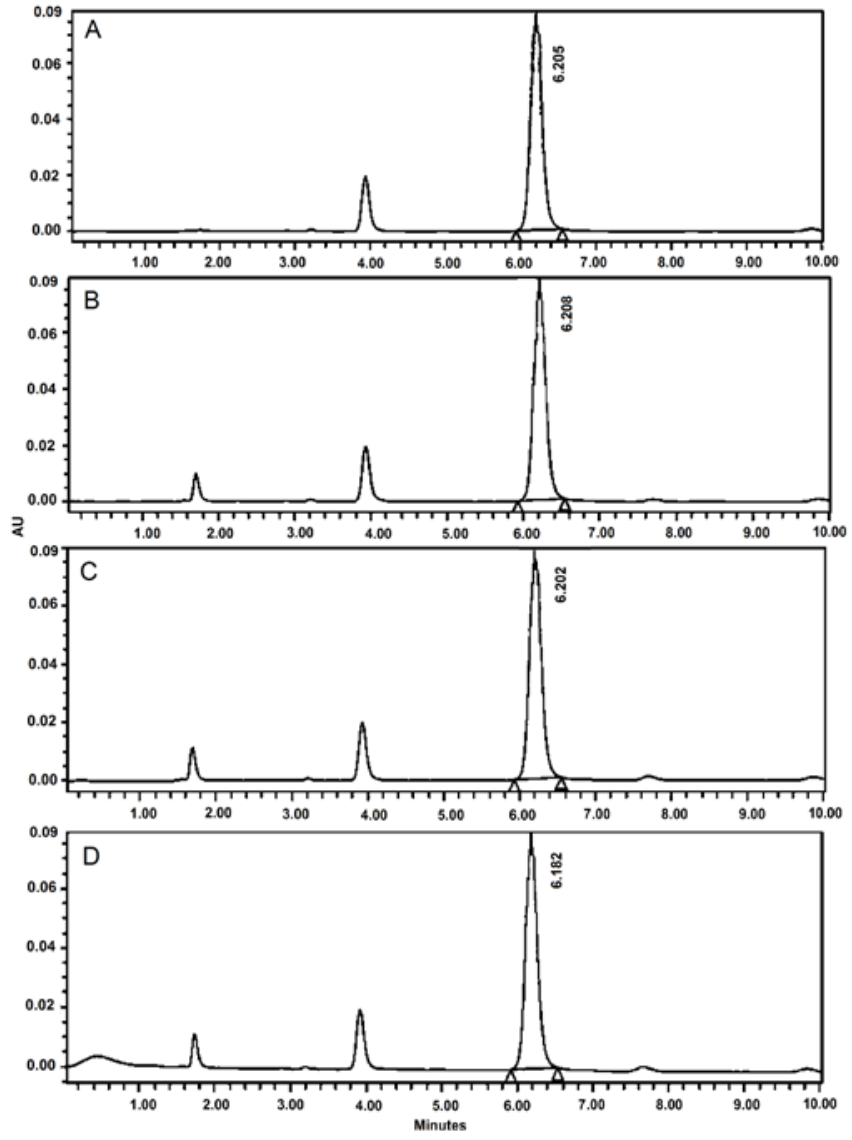

Figure 5. Chromatograms of solution stability at (A) initial time, (B) 6 h, (C) $12 \mathrm{~h}$ and (D) $24 \mathrm{~h}$

A two-level full factorial design was utilized for proper modeling and optimization of process parameters in visible spectroscopy and RP-HPLC methods. With the help of contour plots optimum values of selected factors were identified (Figure 2 and Figure 3). There was a good match between the predicted values and experimental values. A considerable perception was obtained about the effect of variables on the selected response Y. The results of visible and UV spectroscopy showed high linearity correlation coefficient $\left(\mathrm{R}^{2}=0.99\right)$. The percent assay of ABN was determined using both visible and UV spectroscopic methods were found appreciable. Since there was no interference, both the methods can be said to be specific. High values of percent recovery in both studies, RSD values of precision and robustness, values of LOD and LOQ, all being within the specified acceptance limits (Table 4). The two spectroscopic methods were found specific, accurate, and precise with enough robustness and could be applied in the routine estimation of $\mathrm{ABN}$.

The RP-HPLC method developed showed high percent purity of $\mathrm{ABN}$ in tablet formulations. Results of method validation studies in terms of linearity, accuracy, precision, system suitability, LOD and LOQ were within the specified acceptance limits. The developed RP-HPLC method was said to have qualified the validation parameters. Since there was no interference of blank and placebo during the retention time of the analyte, the developed method possessed high specificity. The RSD values of peak areas due to deliberate alterations in flow rate, wavelength and mobile phase compositions being within acceptance limits (Table 5), signifies the high 
robustness of the developed method. Considering the results of forced degradation studies (Table 6) in any study media (acid, alkali, peroxide, reducing) and forced environmental conditions (photolytic, thermal or excess humidity), the developed method conforms to the standard limits. Similar is the case with bench top stability studies (Table 7) where the deviation did not exceed the limits of $2.0 \%$ at $24 \mathrm{~h}$, suggesting that the developed RP-HPLC method is a stability indicating and validated one, thus contributing another new analytical method to the quality control tests of ABN.

\section{Conclusions}

$\mathrm{ABN}$ is an orally active antihypertensive drug used in the treatment of pulmonary atrial hypertension and no official method is reported in any of the pharmacopeias for its routine estimation. The reported hyphenated techniques involve expenditure, time and critical methodologies. Experimental design approach was employed for modeling and optimization of process parameters in visible spectroscopy and RP-HPLC methods. The current research was successful in developing three analytical techniques with the aid of HPLC, UV and visible spectroscopy which were found simple, accurate, precise, robust and stable. The developed methods could be employed for routine estimation of $\mathrm{ABN}$ in bulk and pharmaceutical formulations. The two-level full factorial design approach was effectively used to develop and optimize the spectrophotometric and RP-HPLC methods for ABN estimation.

\section{Acknowledgement}

We sincerely acknowledge Systron Laboratories, Viajayawada, India, for providing necessary facilities to carry out this work.

\section{References}

[1] Higuchi, T., Brochmann-Hansen, E, Pharmaceutical Analysis, CBS publications, New Delhi, 1997.

[2] Douglas, A., Skoog, F., Holler, J, Fundamentals of Analytical Chemistry, Broks/Cole publications, Stamford, 2009.

[3] Willard, H.H., Merritt, L.L., Dean, J.A., Settle, F.A, Instrumental Methods of Analysis, CBS Publishers, New Delhi, 1986.

[4] The Merck Index. An encyclopedia of chemicals drugs and biologics. 14th edition, Merck and Co., New Jersey, 2006.

[5] Martindale. The Complete Drug Reference, 33rd edition, Edited by Sweetman S.C, Pharmaceutical Press, London, 2002.

[6] Nirogi, R., Kandikere, V., Komarneni, P., Aleti, R., Padala, N, "Kalaikadhiban I: LC-ESI-MS/MS method for quantification of ambrisentan in plasma and application to rat pharmacokinetic study,” Biomedical Chromatography, 26 (10). 1150-1156, Oct. 2012.

[7] Dousa, M., Gibala, P, "Rapid determination of ambrisentan enantiomers by enantioselective liquid chromatography using cellulose-based chiral stationary phase in reverse phase mode," Journal of Separation Science, 35 (7), 798-803, Apr. 2012.

[8] Kumar, N.S., Avula, P.R., Telu, V., Sekaran, C.B, "Extractive spectrophotometric determination of ambrisentan," Advanced Pharmaceutical Bulletin, 3 (1). 231-237. Feb. 2013.

[9] Seshamamba, B.S.V., Satyanarayana, P.V.V., Sekaran, C.B, "Spectrophotometric methods for the determination of ambrisentan using charge transfer reagents," Journal of Applied Chemical Reserach, 7 (3). 7-14. Jul. 2013.

[10] Prathyusha, V., Siddartha, B., Sowmya, B., Madhavi, C., Kalyani, $\mathrm{N}$, "A validated UV spectrophotometric method for the estimation of ambrisentan in pure and tablet dosage forms," Inventi Rapid: Pharm Analysis \& Quality Assurance 2014. Article ID Inventi: ppaqa/1266/13. http://www.inventi.in/Article/ppaqa/1266/13.aspx

[11] Nanjappan, S.K., Gandham, N.K, "A stability indicating reversed phase high performance liquid chromatography method for ambrisentan: an endothelin receptor antagonist,” Journal of Chromatographic Science, in press. 2013.

[12] Narayana, M.B.V., Chandrasekhar, K.B., Rao, B.M, “A validated specific stability indicating RPिHPLC assay method for ambrisentan and its related substances,” Journal of Chromatographic Science, in press. 2013.

[13] Ramalingam, S., Rajappan, M., Valliappan, K, "HPLC method for the simultaneous determination of levocetirizine, ambroxol and montelukast in human plasma employing response surface methodology," International Journal of Drug Development and Research, 4 (3). 173-185. Jul. 2012.

[14] Wani, Y.B., Patil, D.D, “An experimental design approach for optimization of spectrophotometric method for estimation of cefixime trihydrate using ninhydrin as derivatizing reagent in bulk and pharmaceutical formulation,” Journal of Saudi Chemical Society, 2013. Online.

[15] Gohel, N.R., Patel, B.K., Parmar, V.K, "Chemometrics assisted UV spectrophotometric and RP-HPLC methods for the simultaneous determination of tolperisone hydrochloride and diclofenac sodium in their combined pharmaceutical formulation," Scientia Pharmaceutica, 81 (4), 983-1001. Dec. 2013.

[16] Vadeya, C.M., Yadav, D.S., Jogia, H.A., Chauhan, P.L, “Design of experiment (DOE) utilization to develop a simple and robust reversed phase HPLC technique for related substances estimation of omeprazole formulations," Scientia Pharmaceutica, 81 (4), 1043-1056. Dec. 2013.

[17] Balakrishna, M., Aziz, U., Prabhakar, R., Suma, C.H, "RP-HPLCPDA method for the analysis of ambrisentan in bulk drugs and pharmaceutical dosage forms,” Int J Chem Pharm Sci, 4 (4), 45-50. Dec. 2013.

[18] Yanmandru, V.K., Murali, D., Rambabu, C., "New visible spectrophotometric methods for determination of ambrisentan," Bull. Pharm Res Poster presentation, Proceedings of APP 1st Annual National Convention, 2012.

[19] Sreenivasulu, J., Nagaraju, C.H.V.S., Rajan, S.T., Eswaraiah, S., Ramana, P.V., "Development and validation of novel stability indicating RP-HPLC method for estimation of related substances and degradation products in Ambrisentan.,” Anal Chem , 14 (1) 2014.

[20] Nageswara Rao, R., Ramakrishna, K., "LC-MS/MS characterization of forced degradation products of ambrisentan: development and validation of a stability-indicating RP-HPLC method" New J Chem Mar. 2014.

[21] Yoshinari, Y., Miho, T., Hideki, H., Keita, H., Yasuo, O., Yuto, Y., Kenichiro, T., Toshimasa, T., Hiroshi, Y., Kunihiko, I., "Simultaneous microdetermination of bosentan, ambrisentan, sildenafil, and tadalafil in plasma using liquid chromatography/tandem mass spectrometry for pediatric patients with pulmonary arterial hypertension," J Pharm Biomed Anal, 89, 227-232. Feb. 2014.

[22] Intenational Conference on Hormonization (ICH) Harmonized Tripartate Guideline. Validation of analytical procedures: Text and Methodology, Q2 (R1). Switzerland: 2005, 1-13. 